\title{
Nonionic emulsion-mediated synthesis of zeolite beta
}

\author{
YUGUO SHEN, YING ZHANG*, CHAO JIN, YING CAO, WEI GAO and LISHAN CUI \\ Department of Materials Science and Engineering, China University of Petroleum, 18 Fuxue Road, \\ Changping District, Beijing 102249, China \\ ${ }^{\dagger}$ The State Key Laboratory of Heavy Oil Processing, China University of Petroleum, 18 Fuxue Road, \\ Changping District, Beijing 102249, China
}

MS received 20 November 2009; revised 6 January 2010

\begin{abstract}
Zeolite beta synthesis was first carried out in a newly developed emulsion system containing nonionic polyoxyethylated alkylphenol surfactant, which showed interesting non-conventional features. Compared to the conventional hydrothermal synthesis of zeolite beta, the reported nonionic emulsion system showed a faster nucleation rate. Furthermore, the emulsion system could stabilize the beta product and retarded its further transformation to ZSM-5 even under the high crystallization temperature at $453 \mathrm{~K}$. Additionally, the beta particle size could be tuned by the adoption of different lengths of alkyl chain in the surfactant and cosurfactant. Control experiments showed each emulsion component played a crucial role in the zeolite beta growth. The approach proposed in this paper might be extended to apply for the syntheses of other types of zeolites with particle size under control.
\end{abstract}

Keywords. Zeolite beta; zeolite ZSM-5; nonionic emulsion system; particle size; crystal transformation.

\section{Introduction}

Zeolite beta was firstly synthesized using tetraethylammonium hydroxide as a structure directing agent (SDA) by Wadlinger of Mobile Corp in 1967, which was the first example of a tridirectional large-pore zeolite with low aluminum content (Wadlinger et al 1967). It is widely used in hydrocracking, hydroisomerization, aromatic alkylation, disproportionation and other organic synthesis processes at present (Camblor et al 1996). Usually, zeolite beta is synthesized by hydrothermal method at mild conditions (Camblor et al 1991). Besides the conventional method, many other methods have been explored such as dry gel conversion method (Hari Prasad Rao et al 1998), F-system synthesis (Liu et al 2001), steamassisted crystallization method (Matsukata et al 2002) and special silicon source technique (Sun et al 2007).

Recently, microemulsion has been used to synthesize zeolite A and Silicalite-1 and the ability of microemulsion to induce rapid crystallization and control crystal morphology has been elaborately demonstrated (Lee and Shantz 2004; Carr and Shantz 2005; Lee and Shantz 2005a, b). However, microemulsion has not yet been applied to synthesize other types of zeolites, especially those crystallized with the templating of SDAs such as beta and ZSM-5. The presence of SDAs would complicate the microemul-

*Author for correspondence (yingzh1977@163.com) sion system and might interfere with the emulsion components and weaken the effects of microemulsion.

Previously, we have described zeolite beta synthesis in an anionic emulsion system containing sodium dodecylbenzenesulfonate (SDBS) surfactant for the first time (Jin et al 2009). As an extension of our previous work, here we synthesized zeolite beta in a nonionic emulsion system composed of polyoxyethylated alkylphenol surfactant stabilized zeolite synthesis mixture droplets dispersed in cyclohexane. To the best of our knowledge, this report represents the first use of nonionic emulsion system to prepare zeolite beta.

\section{Experimental}

The nonionic emulsion synthesis of zeolite beta involved the following steps. Firstly, polyoxyethylated alkylphenol surfactant (OP), alkanol cosurfactant and cyclohexane were mixed under stirring. Then the conventional zeolite beta synthesis mixture with the molar composition of TEAOH : $\mathrm{Al}_{2} \mathrm{O}_{3}: \mathrm{SiO}_{2}: \mathrm{H}_{2} \mathrm{O}$ to $9: 0 \cdot 25: 25: 490$ was prepared following the procedure reported (Modhera et al 2009) and subsequently added to the first mixture containing OP to obtain the emulsion system. Finally, the emulsion system was transferred to Teflon-lined stainless steel autoclaves and crystallized at $413 \mathrm{~K}$ for $48 \mathrm{~h}$ and then $443 \mathrm{~K}$ for $48 \mathrm{~h}$. For comparison, the conventional zeolite beta synthesis was also carried out under the same crystallization conditions. Notably, when the crystalliza- 
tion curves were investigated, syntheses were carried out at $413 \mathrm{~K}$ for $0-170 \mathrm{~h}$ and when the transformation of beta to ZSM-5 was investigated, syntheses were carried out at $413 \mathrm{~K}$ for $48 \mathrm{~h}$ and then $433,443,448$ or $453 \mathrm{~K}$ for $48 \mathrm{~h}$. In the final results, the compositions of the emulsion systems were described using weight fractions of emulsion components. As an example, $50 \mathrm{H}: 40 \mathrm{~S}: 10 \mathrm{Z}$ represents $50 \mathrm{wt} \%$ of cyclohexane, $40 \mathrm{wt} . \%$ of OP + alkanol and $10 \mathrm{wt} . \%$ of zeolite mixture and $\mathrm{H}$ is cyclohexane, $\mathrm{Z}$ is zeolite mixture and $\mathrm{S}$ is OP plus alkanol with the weight ratio of OP : alkanol to $2: 1$.

\section{Results and discussion}

\subsection{Effect of nonionic emulsion}

Figure 1 shows the XRD patterns of the two samples synthesized from the conventional synthesis system and the nonionic emulsion system. The calculated interplanar spacings of both samples match well with the reported values of zeolite beta (Wadlinger et al 1967). The presence of both broad and sharp peaks at 7.8 and $22.7^{\circ}$ (marked by " ") is the typical characteristic of beta structure (Camblor et al 2001). Notably, the beta sample synthesized from the nonionic emulsion system shows stronger peak intensity than that of the conventional beta sample, indicating the nonionic emulsion system favours the crystallization of zeolite beta. Figure 2 shows the crystallization curves of the beta samples synthesized at $413 \mathrm{~K}$ for different crystallization times. It can be found that the nucleation rate of the nonionic emulsion system sample is greatly shortened. The conventional beta sample nucleates within $0-50 \mathrm{~h}$, while the emulsion system sample finishes nucleation after $30 \mathrm{~h}$. To determine the effect of individual emulsion component on the nucleation

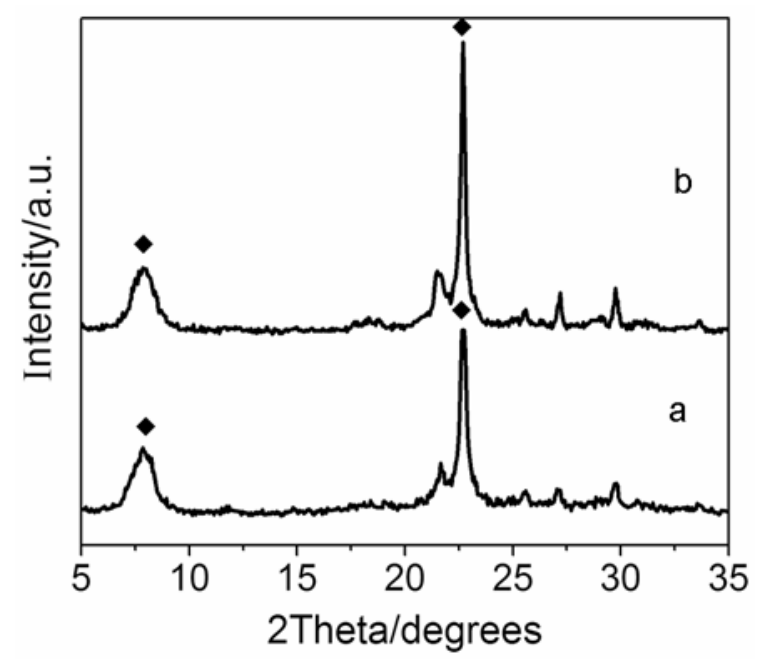

Figure 1. X-ray diffraction patterns of beta samples synthesized from (a) the conventional synthesis system and (b) the nonionic emulsion system of $40 \mathrm{H}: 50 \mathrm{~S}: 10 \mathrm{Z}$. promotion, six control experiments were performed including syntheses containing (i) butanol only, (ii) butanol and OP-10 only, (iii) OP-10 only, (iv) cyclohexane only, (v) OP-10 and cyclohexane only, and (vi) cyclohexane and butanol only. The syntheses (i) and (ii) both produced amorphous XRD patterns, suggesting that the existence of butanol suppresses the crystal formation. The syntheses (iii)-(vi) all produced weak XRD patterns compared to the emulsion sample containing all the three components, which had the highest crystallinity. The above results indicate that each emulsion component plays a critical role in the growth enhancement of the beta material. The cyclohexane may act to solvate the hydrophobic chain of the surfactant, the butanol to lower the interfacial tension, and the surfactant (and butanol) to interact with the aluminosilicate species in solution via van der Waal's forces. The emulsion inducing rapid growth was also reported by Shantz et al when they investigated the nonionic-microemulsion mediated growth of zeolite A (Carr and Shantz 2005). They believed that the nonionic surfactant interacted with the aluminosilicate precursors, which led to the increase of local concentration of these precursors and the final quick growth of zeolite crystal.

\subsection{Particle size control}

To investigate the influence of surfactant identity on the zeolite morphology, we have used three kinds of polyoxyethylated alkylphenol surfactants with ethoxy (EO) numbers of 7.5, 10 and 15 (denoted as OP-7.5, OP-10 and OP-15) respectively as the surfactants to synthesize the zeolite beta. Figure 3 shows the SEM images of the beta samples synthesized using different surfactant systems with the emulsion composition of $40 \mathrm{H}: 50 \mathrm{~S}: 10 \mathrm{Z}$. From

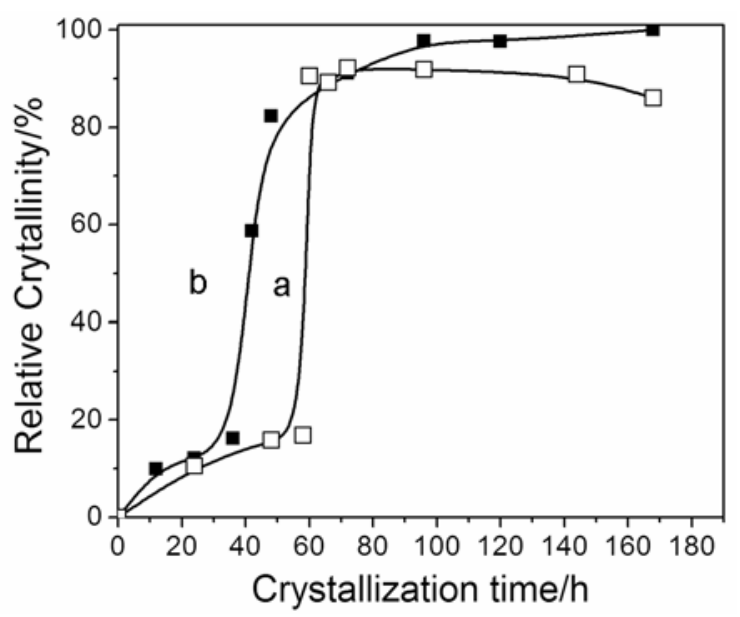

Figure 2. The crystallization curves of the beta samples crystallized at $413 \mathrm{~K}$ from (a) the conventional synthesis system and (b) the nonionic emulsion system of $40 \mathrm{H}: 50 \mathrm{~S}: 10 \mathrm{Z}$. 

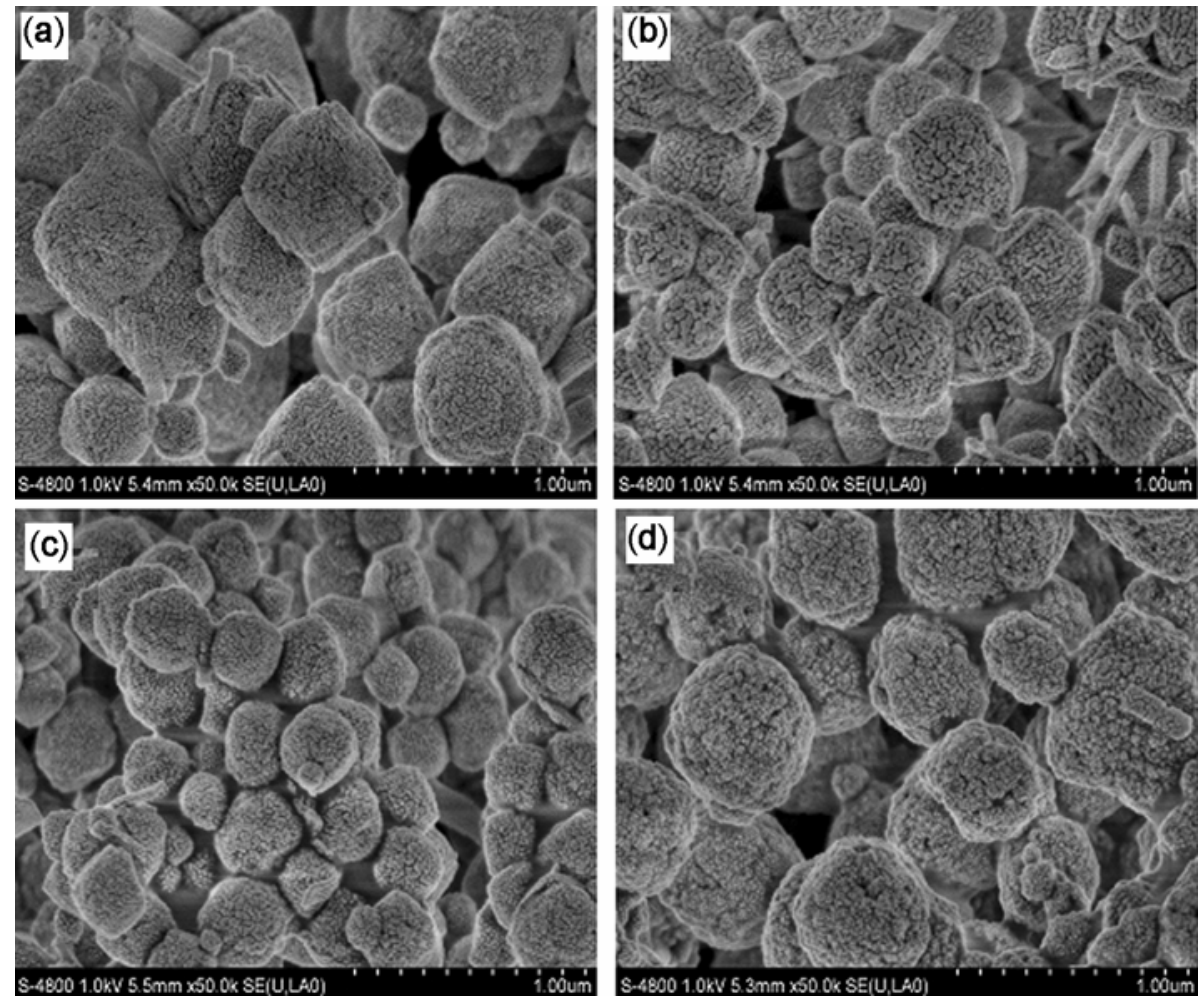

Figure 3. The SEM images of the beta samples synthesized based on the emulsion composition of 40H : 50S : 10Z: (a) butanol + OP-7.5; (b) butanol + OP-10; (c) butanol + OP15; (d) decanol + OP-10.

the SEM images (figures $3 \mathrm{a}-\mathrm{c}$ ) of the corresponding beta samples using these surfactants, it can be obviously seen that with the increase of the ethoxy (EO) numbers from 7.5 to 10 and 15 , the particle sizes of zeolite beta decrease from $600 \mathrm{~nm}$ to $400 \mathrm{~nm}$ and $300 \mathrm{~nm}$. Similar particle size variation is also observed when the alkyl chain length of the cosurfactant is changed. Specifically, when decanol substitutes for butanol, the particle sizes increase from $400 \mathrm{~nm}$ to $600 \mathrm{~nm}$ (figures $3 \mathrm{~b}$ and d). The similar impacts of surfactant identity on the zeolite morphology have been reported in the nonionic microemulsion synthesis of zeolite A (Carr and Shantz 2005). This indicates that in the emulsion-mediated synthesis of zeolite beta, the particle size can be tuned by the adoption of different lengths of alkyl chains in the surfactants and cosurfactants. This approach might be extended to apply for synthesizing other types of zeolites to control particle size.

\subsection{The transformation of zeolite beta to ZSM-5}

In the zeolite synthesis process, the outcome is most frequently kinetically controlled (Cundy and Cox 2005) and the desired product is frequently at metastable states. Figure 4 is the XRD patterns of beta samples synthesized at different crystallization temperatures. For the conventional zeolite beta synthesis (figure 4A), beta transforms to thermodynamically stable ZSM-5 when the crystallization temperature is raised to $448 \mathrm{~K}$. However, for the emulsion synthesis of $40 \mathrm{H}: 50 \mathrm{~S}: 10 \mathrm{Z}$ (figure 4B), the beta can be stablized until the crystallization temperature is up to $448 \mathrm{~K}$ and finally transforms to ZSM-5 when the crystallization temperature further increases to $453 \mathrm{~K}$. Surprisingly, for the emulsion synthesis of $40 \mathrm{H}: 40 \mathrm{~S}: 20 \mathrm{Z}$ (figure 4C), even under the crystallization temperature of $453 \mathrm{~K}$, the crystal product still keeps as zeolite beta structure. This result proves that the nonionic emulsion can stabilize the beta product under the high temperature up to $453 \mathrm{~K}$. This stabilizing effect is also observed by Kong et al when they synthesized small crystal zeolite beta in a biphasic $\mathrm{H}_{2} \mathrm{O}-\mathrm{CTAB}$-alcohol system (Kong et al 2009).

\section{Conclusions}

Well-crystallized beta zeolites are successfully synthesized for the first time in the nonionic emulsions. The presence of nonionic emulsion components quickens the nucleation rate of beta crystallization process and retards the transformation of beta to ZSM-5 even at the higher crystallization temperature of $453 \mathrm{~K}$. Control experiments indicate that all components of the emulsion play important roles in the crystal growth. Additionally, the beta particle size can be tuned by varying the alkyl chain 

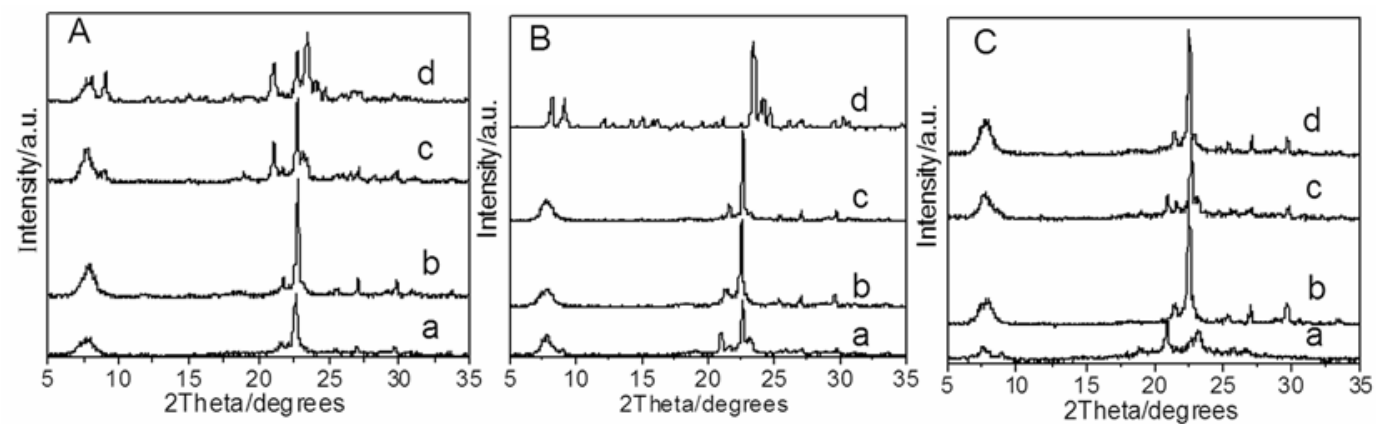

Figure 4. The XRD patterns of the beta samples from (A) the conventional synthesis systems and the nonionic emulsion systems with the composition of (B) $40 \mathrm{H}: 50 \mathrm{~S}: 10 \mathrm{Z}$ and (C) $40 \mathrm{H}: 40 \mathrm{~S}: 20 \mathrm{Z}$ crystallized at $413 \mathrm{~K}$ for $48 \mathrm{~h}$ and then heated to $433 \mathrm{~K}$ (a), $443 \mathrm{~K}$ (b), $448 \mathrm{~K}$ (c) or $453 \mathrm{~K}$ (d) for $48 \mathrm{~h}$.

length of the surfactant and cosurfactant involved in the emulsion synthesis system.

\section{Acknowledgements}

This work was supported by the National Natural Science Foundation of China (Grant No. 20606038) and National Basic Research Program of China (Grant No. 2004CB 217806). The authors thank Microstructure Laboratory for Energy Materials for SEM characterization.

\section{References}

Camblor M A, Barrett P A, Díaz-Cabañas M J, Villaescusa L A, Puche M, Boix T, Pérez E and Koller H 2001 Micropor. Mesopor. Mater. 4811

Camblor M A, Corma A and Valencia S. 1996 Chem. Commun. 2365

Camblor M A, Mifsud A and Perez-Pariente J 1991 Zeolites 11 792

Carr C S and Shantz D F 2005 Micropor. Mesopor. Mater. 85284
Cundy C S and Cox P A 2005 Micropor. Mesopor. Mater. 821

Hari Prasad Rao P R, Ueyama K and Matsukata M 1998 Appl. Catal. A166 97

Jin C, Zhang Y, Gao W and Cui L S 2010 Int. J. Mod. Phys. B24 3236

Kong L, Chen H, Tai J, Shen J, Zhang S and Chen J 2009 Mater. Lett. 63343

Lee S and Shantz D F. 2004 Chem. Comm. 680

Lee S and Shantz D F. 2005a Chem. Mater. 17409

Lee S and Shantz D F. 2005b Micropor. Mesopor Mater. 86 268

Liu Z, Ohsuna T, Terasaki O and Camblor M A $2001 \mathrm{~J}$. Am. Chem. Soc. 1235370

Matsukata M, Osaki T, Ogura M and Kikuchi E. 2002 Micropor. Mesopor. Mater. 561

Modhera B, Chakraborty M, Parikh P A and Jasra R V 2009 Cryst. Res. Technol. 44379

Sun J, Zhu G, Chen Y, Li J, Wang L, Peng Y and Qiu S 2007 Micropor. Mesopor. Mater. 102242

Wadlinger R L, Kerr G T and Rosinski E J 1967 U.S. Patent 3308069 